\title{
IOT Based Cotton Dust Monitoring System in Textile Industry
}

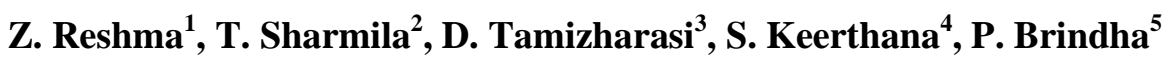

Scholars, Department of Electronics and Communication, Velalar College of Engineering and Technology,

$$
\text { Erode, India }{ }^{1,2,3,4}
$$

Assistant Professor, Department of Electronics and Communication, Velalar College of Engineering and Technology,

$$
\text { Erode, India }{ }^{5}
$$

\begin{abstract}
IOT based cotton dust monitoring system in textile industry is used to monitor the concentration of cotton dust in textile industry. The system uses Wi-Fi technology to transmit the collected data over a wide range. Optical dust sensor is used to measure the cotton dust level. DHT11 sensor is used to measure humidity and temperature level. The cotton dust, humidity and temperature level are monitored in the mobile application and also displayed in textile industry using LCD. If the concentration of cotton dust goes beyond the permissible limit (750 microgram), an indication is given in the textile industry using buzzer and also mail is sent to the Industry management.
\end{abstract}

Keywords: Cotton dust concentration, Optical dust sensor, Arduino UNO, IOT.

\section{I.INTRODUCTION}

Cotton dust is defined as the dust present in air during the handling or processing of cotton. Dust from raw cotton may contain a mixture of substance including bacteria, fungi, pesticides and other contaminants. The types of cotton dust are Trash (Above 500 micron) dust, Dust (50-500 micron), Micro dust (15-50 micron), Breathable dust (Below 15 micron). Textile industry is the second largest industry next to agriculture with number of sections like opening, packing, carding, combing, roving, spinning, winding, warping, slashing, weaving, knitting which are used to convert cotton fiber into a finished fabric or garment. The permissible exposure limits for cotton dust in opening, packing and spinning is 200 microgram per cubic meter and in slashing, weaving, knitting is 750 microgram per cubic meter. Over 60 million people worldwide working in cotton or textile industry. They suffer from diseases like cancer, cough, phlegm, wheezing, Byssinosis due to constant exposure of cotton dust. So it is important to measure the concentration of cotton dust to protect the people working in the industry. Humidity and temperature prevailing in the textile industry is measured, since they affect the cotton dust density in the industry.

\section{II.EXISTING SYSTEM}

In the existing system, Zigbee technology is used to establish wireless networking. The system measures all inhalable dust particles which pm1.0, pm2.5, pm10. MSP430F149 microcontroller is used to perform computational task. It is an ultra low power microcontroller. Akala G1 dust particles sensor is used to measure the concentration of dust, which uses light scattering principle and MIE theory to measure dust density. The dust sensor detects particles greater than 1 micron. The analog dust concentration value is converted into digital value by using analog to digital converter in microcontroller and it is send to the router. The ceramic piezoelectric generator is used to power the system.

\section{Limitation}

The system uses Zigbee technology to transmit the dust concentration. Zigbee technology is a short range wireless technology.

\section{PROPOSED SYSTEM FOR MONITORING OF COTTON DUST}

The proposed system consists of optical dust sensor, DHT11 sensor and Arduino UNO. This system uses Wi-Fi module to transmit collected sensor data to remote distance. The concentration of cotton dust in textile industry is measured 
Vol. 8, Issue 2, February 2019

using Optical dust sensor which measures cotton dust of greater than 1 micron. The DHT11 sensor measures both moisture and temperature. Arduino UNO acts as brain of the system and it performs the computational task. The optical dust sensor and DHT11 sensor data are send to the Arduino UNO, which is a microcontroller board based on microchip ATmega328p. The cotton dust concentration, humidity and temperature value are displayed in the LCD display in the textile industry. If the concentration of cotton dust level goes beyond the permissible limit, an indication is given by using buzzer in the textile industry. The cotton dust concentration, humidity and temperature value are viewed in the mobile application (blynk) using Wi-Fi module. An alert mail is send to the industry management indicating that the cotton dust concentration is greater than permissible limit (750 microgram).

\section{BLOCK DIAGRAM}

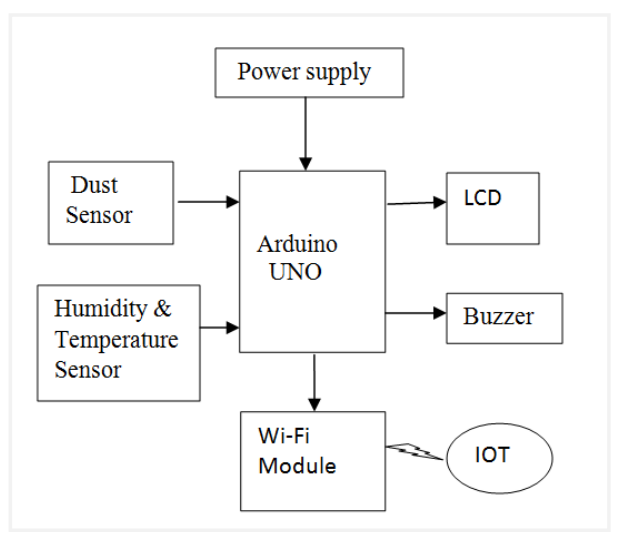

\section{Hardware Module}
1. Optical Dust Sensor
2. DHT11 Sensor
3. Micro-controller:-Arduino UNO
4. Wi-Fi Module
5. LCD
6. BUZZER

\section{Software Module}

Arduino IDE

\section{Description}

Optical dust sensor gives the concentration of cotton dust in terms of analog voltage which is proportional to cotton dust density. It works on light scattering principle. The analog value is given to Analog input pin 1 of the Arduino UNO which has built-in ADC to convert the analog value into digital value. The concentration of cotton dust is in terms of microgram/meter cube. DHT11 sensor gives the temperature and humidity level in digital form. The temperature value is in terms of ${ }^{\circ} \mathrm{C}$ and the humidity value in terms of \% RH. For measuring humidity, the sensor uses humidity sensing components which has two electrodes with moisture holding substrate between them. When humidity changes, conductivity of the moisture holding substrate changes or the resistance between the electrodes changes. This change in resistance is measured and processed by the IC which makes it ready to be read by Arduino UNO. For measuring temperature, the sensor uses a NTC (Negative Temperature Coefficient) temperature sensor or a thermistor. DHT11 sensor is connected to Digital I/O pin 8 of the Arduino UNO. The Data pins (D4, D5, D6, D7) of LCD are connected to Digital I/O pins $(4,5,6,7)$ of Arduino UNO to display the cotton dust concentration and humidity and temperature value. Buzzer is connected to Digital I/O pin 11 of the Arduino UNO and it gives indication if the concentration level goes beyond permissible limit. The Wi-Fi Module ESP8266 is connected to Arduino UNO which is used to view the cotton dust concentration and humidity and temperature value in the remote distance. Arduino IDE is used to program Arduino UNO. Blynk library is downloaded and it is added to Arduino IDE. The cotton dust concentration, humidity and temperature value are monitored in mobile application blynk by creating an individual account using mail ID. An indication mail is sent to the industry management by the blynk application to notify that the dust level is high. 


\section{IJARCCE}

Vol. 8, Issue 2, February 2019

\section{RESULT}

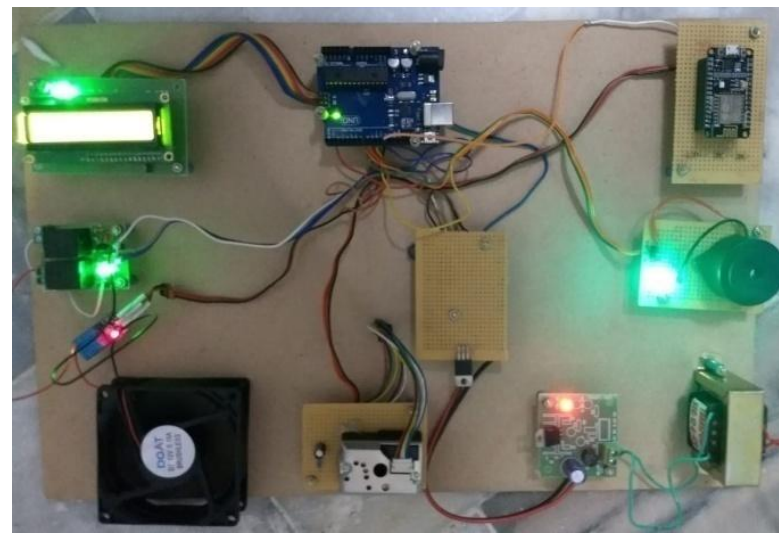

Figure 1: Experimental setup of the system.

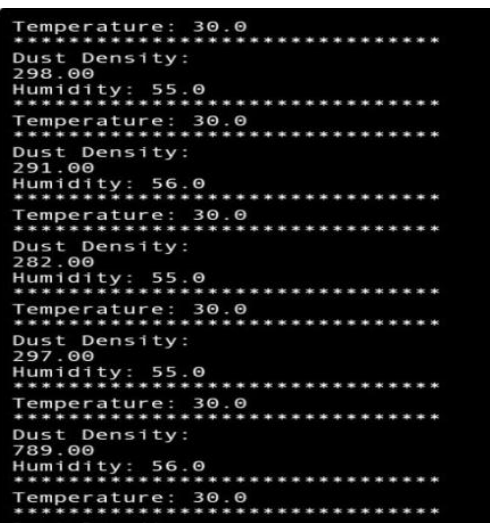

Figure 2: Cotton Dust Density, Humidity and Temperature values in blynk application.

TABLE I

COTTON DUST DENSITY, HuMidity AND TEMPERATURE VALUE

\begin{tabular}{|c|c|c|}
\hline $\begin{array}{c}\text { Cotton dust } \\
\text { concentration } \\
\text { (microgram) }\end{array}$ & Temperature ${ }^{\mathbf{}} \mathbf{C}$ & $\begin{array}{c}\text { Humidity } \\
\text { \% } \mathbf{R H}\end{array}$ \\
\hline 93 & 29 & 68 \\
\hline 189 & 29 & 66 \\
\hline 222 & 29 & 63 \\
\hline 456 & 30 & 59 \\
\hline 789 & 30 & 56 \\
\hline
\end{tabular}

\section{Advantages}

- Installation is simple.

- $\quad$ Remote distance monitoring system.

- $\quad$ Low cost implementation.

\section{VI.CONCLUSION}

IOT Based Cotton Dust Monitoring System in Textile Industry gives the real time monitoring of cotton dust concentration and humidity and temperature value. It is used as a solution to overcome the problem of collection of data manually and also use of technology with shorter range. This system uses Wi-Fi as wireless technology to continuously transmit data in wide range with low cost. It can be implemented in Textile industry, Spinning mill, Power loom. If the cotton dust value increases above permissible limit, necessary actions (Dust Filtration, Air Purifier) should be taken by the Industry management to safeguard people working in the Industry. 


\section{IJARCCE}

Vol. 8, Issue 2, February 2019

\section{REFERENCES}

[1]. Hong He, Yannan Gao and Zhihong Zhang, "The Urban Road Dust Monitoring System Based on ZigBee," 28th Chinese Control and Decision Conference (CCDC), pp.1793-1796, 2016.

[2]. B.M. Sangeetha, M. Rajeshwari, S. Atharsha, K. Saranya Sri and S. Ramya, "Cotton Dust Level in Textile Industries and Its Impact on Human," International Journal of scientific and Research Publications, Vol.3, 2013

[3]. Goncalo Marques, Cristina Roque Ferreira and Rui Pitarma, "A System Based on the Internet of Things for Real-Time Particle Monitoring in Buildings," International Journal of Environmental Research and Public Health, pp.1-14, 2018.

[4]. Wonseok choi, Dokyung hwang, Jongpil kim and Jangmyung lee, "Fine dust monitoring system based on Internet of Things," International Conference on information and Communication Robotics, 2016.

[5]. S. V. Chavan, S. K. Tilekar, P.V. Mane-Deshmukh and B. P. Ladgaonkar, “ARM Microcontroller Based Wireless Sensor Network to Monitor Environmental Parameters of Textile Industry," International Journal of Advanced Research in Computer Science and Software Engineering, Vol.7, Issue 5, 2017.

[6]. M. Saravanan, M. Jagadesh, V. Deepan, R. Divya and S. Gowri Manohari, "Smart Data Monitoring System for Power Loom Using IOT," International Journal of Pure and Applied Mathematics, Vol.119, pp 937-947, 2018.Saiba P A, Afeefa M U, Aruna T S, Clincy Jose, Radhika V M "Density Based Traffic Signal System using PIC Microcontroller "International Journal of Computer Trends and Technology (IJCTT) -Volume 47 Number 1 May 2017 